\title{
Action Potential Timing Determines Dendritic Calcium during Striatal Up-States
}

\author{
Jason N. D. Kerr and Dietmar Plenz \\ Unit of Neural Network Physiology, Laboratory of Systems Neuroscience, National Institute of Mental Health, Bethesda, Maryland 20892
}

Up-states represent a key feature of synaptic integration in cortex and striatum that involves activation of many synaptic inputs. In the striatum, the sparse firing and tight control of action potential timing is in contrast to the large intracellular membrane potential depolarizations observed during the up-state. One hallmark of striatal spiny projection neurons is the delay to action potential generation in both up-states and suprathreshold depolarization by somatic current injection. By studying somatic and dendritic intracellular calcium $\left(\left[\mathrm{Ca}^{2+}\right]_{\mathrm{i}}\right)$ transients during spontaneous up-states in cortex-striatum-substantia nigra organotypic cultures, we show that the delay between up-state onset and action potential generation determines dendritic peak $\left[\mathrm{Ca}^{2+}\right]_{\mathrm{i}}$. Peak $\left[\mathrm{Ca}^{2+}\right]_{\mathrm{i}}$ from single action potentials reached maximum values when action potentials were close to up-state onset and sharply decayed to near subthreshold up-state $\left[\mathrm{Ca}^{2+}\right]$ levels as a function of time ( $\tau=47 \pm 26 \mathrm{msec}$ for tertiary dendrite). Similarly, a precisely timed action potential elicited during subthreshold up-states through somatic current injection established that the delay between up-state onset and action potential generation is the critical variable that controls peak $\left[\mathrm{Ca}^{2+}\right]_{\mathrm{i}}$. Blocking NMDA channels internally with high intracellular $\mathrm{Mg}^{2+}\left(\left[\mathrm{Mg}^{2+}\right]_{\mathrm{i}}\right)(10$ $\mathrm{mm}$ ) abolished the dependency of peak $\left[\mathrm{Ca}^{2+}\right]_{\mathrm{i}}$ on action potential timing during spontaneous up-states. Finally, high $\left[\mathrm{Mg}^{2+}\right]_{\mathrm{i}}$ specifically blocked $\left[\mathrm{Ca}^{2+}\right]_{\mathrm{i}}$ transients that resulted from local NMDA application in conjunction with backpropagating action potentials. We conclude that precisely timed, single action potentials during striatal up-states control peak dendritic calcium levels. We suggest that this mechanism might play an important role in synaptic plasticity of the corticostriatal pathway.

Key words: action potential backpropagation; spike timing; calcium; NMDA; plasticity; fura-2; organotypic culture; spiny projection neuron; dendritic processing; up-state; down-state; cortex; striatum; substantia nigra; electrophysiology; imaging

\section{Introduction}

Up-states are large intracellular membrane potential fluctuations in striatal spiny projection neurons (Wilson and Kawaguchi, 1996; Stern et al., 1997) and cortical pyramidal neurons (Lampl et al., 1999). They occur spontaneously in vivo and in systems with intact cortical circuitry in vitro (Plenz and Aertsen, 1996; Plenz and Kitai, 1998; Kerr and Plenz, 2002) and are brought about by highly coordinated synaptic activation (Wilson and Kawaguchi, 1996; Plenz and Kitai, 1998; Stern et al., 1998; Kerr and Plenz, 2002). Action potential generation occurs only during up-states, so given the tight correlation of up-state transitions between nearby neurons (Stern et al., 1998; Lampl et al., 1999) and the modulation of up-states by neurotransmission (Plenz and Aertsen, 1996; Lewis and O’Donnell, 2000), up-states are a key feature of synaptic integration during network activation.

Because the striatum receives the majority of cortical inputs to the basal ganglia, striatal action potential generation is important

\footnotetext{
Received Oct. 1, 2003; revised Dec. 3, 2003; accepted Dec. 5, 2003.

We thank Craig Stewart for preparation of cultures and Drs. John Beggs, Uwe Czubayko, Chip Gerfen, and Rea Ravin for comments on previous versions of this manuscript.

Correspondence should be addressed to Dr. Dietmar Plenz, Unit of Neural Network Physiology, Laboratory of Systems Neuroscience, National Institute of Mental Health, Building 36, Room 2D-26, 9000 Rockville Pike, Bethesda, MD 20892. E-mail: plenzd@intra.nimh.nih.gov.

J. N. D. Kerr's present address: Department of Cell Physiology, Max Planck Institute for Medical Research, Johnstrasse 29, Heidelberg D-69120, Germany. E-mail: jason@mpinf-heidelberg.mps.edu.

D01:10.1523/JNEUROSCI.4475-03.2004

Copyright $\odot 2004$ Society for Neuroscience $\quad$ 0270-6474/04/240877-09\$15.00/0
}

for relaying convergent cortical information to basal ganglia output structures (for review, see Gerfen and Wilson, 1996). The first step in this process is the transition of a spiny projection neuron into the up-state. Although the majority of these neurons simultaneously transition into an up-state (Stern et al., 1998), not all fire action potentials during this period (Wickens and Wilson, 1998; Sandstrom and Rebec, 2003), and the action potentials that are elicited are not tightly correlated between different neurons (Stern et al., 1998). These intracellular findings correspond well with extracellular studies both in primates (Hikosaka et al., 1989b) and rodents (Jog et al., 1999; Sandstrom and Rebec, 2003), demonstrating that many striatal neurons are quiescent or display low levels of action potential discharge. The reluctance to fire action potentials is further documented by the multitude of inwardly rectifying potassium currents (Nisenbaum et al., 1994; Nisenbaum and Wilson, 1995) in spiny projection neurons that delay action potential generation in response to intracellular membrane potential depolarizations.

These hallmarks of striatal physiology raise the question of how much of an influence do single action potentials have on striatal function during up-states? In the cortex, during low levels of synaptic activity, single action potentials precisely timed to coincide with synaptic inputs critically regulate dendritic intracellular calcium $\left(\left[\mathrm{Ca}^{2+}\right]_{\mathrm{i}}\right.$ ) levels (Koester and Sakmann, 1998) and synaptic plasticity (Magee and Johnston, 1997; Markram et al., 1997; for review, see Stuart and Hausser, 2001). In the present 
study, we demonstrate that the time delay between up-state transition and first action potential generation determines dendritic calcium levels in striatal neurons. The resulting timing function originates from the interaction between the backpropagating action potential and NMDA receptor activation. Together, these findings emphasize the importance of single action potentials in striatal function and provide the first step in merging the concept of spike-time-dependent plasticity with the concept of up-states.

\section{Materials and Methods}

For the preparation of cortex-striatum-substantia nigra organotypic cultures, coronal rat slices $(350-500 \mu \mathrm{m}$ at postnatal days $0-2)$ from the cortex, striatum, and substantia nigra were combined and grown on a coverslip for $31 \pm 7 \mathrm{~d}$ ( $n=29$ cultures) (Plenz and Kitai, 1998; Kerr and Plenz, 2002). For whole-cell patch recording, cultures were submerged in artificial CSF (ACSF) containing (in $\mathrm{mM}$ ): $126 \mathrm{NaCl}, 0.3 \mathrm{NaH}_{2} \mathrm{PO}_{4}, 2.5$ $\mathrm{KCl}, 0.3 \mathrm{KH}_{2} \mathrm{PO}_{4}, 1.6 \mathrm{CaCl}_{2}, 1.0 \mathrm{MgCl}_{2}, 0.4 \mathrm{MgSO}_{4}, 26.2 \mathrm{NaHCO}_{3}$, and 11 D-glucose saturated with $95 \% \mathrm{O}_{2}$ and $5 \% \mathrm{CO}_{2}$ at $35.5 \pm 0.5^{\circ} \mathrm{C}(300 \pm$ $5 \mathrm{mOsm}$ ). The intracellular patch pipette solution contained (in $\mathrm{mm}$ ): $132 \mathrm{~K}$-gluconate, $6 \mathrm{KCl}, 8 \mathrm{NaCl}, 10 \mathrm{HEPES}, 2 \mathrm{Mg}$-ATP, $0.39 \mathrm{Na}$-GTP and was supplemented with $100 \mu \mathrm{M}$ fura-2 (pentapotassium salt; Molecular Probes, Eugene, OR) and 0.2\% Neurobiotin (Vector Laboratories, Burlingame, CA), with $\mathrm{pH}$ adjusted to 7.2-7.4 and a final osmolarity of $290 \pm 10 \mathrm{mOsm}$. The open pipette resistance was 4-6 M .

The recording chamber was mounted on an inverted microscope (IX70; Olympus, Tokyo, Japan), placed on a custom-made sliding table allowing for a change in field of view during the experiment. Intracellular signals were recorded using an Axopatch 1-D amplifier with CV-4 1x head stage (Axon Instruments, Foster City, CA). After the formation of a gigaseal, electrode capacitance was compensated for and serial resistance compensation was switched off. Data were recorded in current clamp, preamplified (Cyberamp380; Axon Instruments), digitized at $10 \mathrm{kHz}$ for voltage and $5 \mathrm{kHz}$ for current, and stored in continuous stream mode using the CED1401plus (Cambridge Electronic Design, Cambridge, UK). Electrophysiological data analysis was performed in Spike2 (Cambridge Electronic Design), Origin version 7.0 (Microcal, Southampton, MA), and Excel (Microsoft, Seattle, WA). All membrane potential values were corrected for K-gluconate liquid junction potential. Striatal spiny projection neurons were identified by a spherical soma size of $10-12 \mu \mathrm{m}$ in diameter using Hoffmann Modulation Contrast optics (40×) and, after breakthrough, were also identified by their polarized resting membrane potential, inward and outward rectification, delayed action potential firing in response to somatic current injections, and the presence of dendritic spines (for details, see Kerr and Plenz, 2002).

To increase temporal precision in evoked action potential firing, exponentially decaying somatic current pulses were used (see Fig. $4 A$, inset). The variability of spontaneous up-states did not allow us to predict beforehand how many, if any, action potentials would be generated during up-states. However, because of the low firing rate during spontaneous up-states, current-evoked action potentials could be easily distinguished from spontaneous action potentials.

DL-2-amino-5-phosphonovalerate (DL-APV, $50 \mu \mathrm{M}$; Sigma, St. Louis, $\mathrm{MO}$ ) and 6,7-dinitro-quinoxaline-2,3(1H,4H)-dione (DNQX, $30 \mu \mathrm{M}$; Sigma) were solved in ACSF for bath application. NMDA (100 $\mu \mathrm{M}$ in ACSF; Sigma) was locally applied with a patch pipette (internal tip diameter of $\sim 5 \mu \mathrm{m}$ ) positioned under visual control close to the dendrites of the neuron from which we recorded. NMDA was applied using single pressure pulses ( $\sim 4$ psi, 10 msec duration; Picospritzer II; Parker Hannifin), and responses were monitored from somatic recordings. To ensure that NMDA application was reaching the dendritic region of the neuron, initial experiments were done under visual control, and the pressure pulse profile was mapped extensively using Oregon Green BAPTA-1 (100 $\mu \mathrm{m}$; Molecular Probes) in the pipette (see Fig. $7 F)$. To evoke action potentials with identical exponentially decaying current pulses, current pulses were first adjusted to elicit single action potentials in combination with local NMDA application. In the absence of NMDA application, a depolarizing square-wave pulse at the soma was used to compensate for the lack of somatic membrane potential depolarization while eliciting action potentials.

For intracellular calcium imaging, neurons were loaded with a $100 \mu \mathrm{M}$ concentration of the calcium-sensitive indicator dye fura-2 (for details, see Kerr and Plenz, 2002). Briefly, fluorescence measurements were started 10-15 min after break-in (Helmchen et al., 1996), and one to two primary dendrites and corresponding higher-order dendrites were analyzed simultaneously. Dye excitation was achieved with a polychromatic illumination system coupled to the microscope via a quartz light guide and wavelength selection via diffraction grating (TILL Photonics, $\mathrm{Mu}-$ nich, Germany). Fluorescence measurements were made with a thermoelectrically cooled CCD camera using commercially available software (Tillvision version 4.0; TILL Photonics). Overview pictures (1 sec exposure) were taken at the completion of each experiment for determining individual regions of interest (ROIs). ROIs were grouped into primary, secondary, and tertiary dendrites, with each area defined by dendritic branching points. Background was defined as the area adjacent to each ROI that was located outside the neuron of interest. Calculations for ROIs and associated changes in $\left[\mathrm{Ca}^{2+}\right]_{i}$ were measured with singlewavelength imaging $(380 \mathrm{~nm})$ and expressed as $\Delta F / F$ for each frame as $\left(F_{\mathrm{i}}-F_{0}\right) / F_{0}$ and expressed as percentage change, where $F_{0}$ indicates the baseline fluorescence obtained from the average of 10-20 frames during the down-state and $F_{\mathrm{i}}$ indicates individual fluorescence measures at frame i. Background correction was calculated for each image frame and subtracted from both $F_{\mathrm{i}}$ and $F_{0}$.

Custom-written routines in assembler code scanned the intracellular membrane potential on-line in order for detection of up-state transitions as well as down-state periods. The detection was based on on-line statistical membrane potential analysis with a threshold calculated at $5 \times \mathrm{SE}$ during periods of low spontaneous activity (down-states). Positive threshold-crossing by the membrane potential indicated a transition to the up-state, whereas negative threshold-crossing indicated a return to a down-state. On average, threshold for up-state detection was $-66 \pm 4$ $\mathrm{mV}$. Thus, neurons were depolarized on average by $18 \pm 5 \mathrm{mV}$ before the first frame was captured. On average, cells spent $90 \%$ of their time below threshold. Down-state imaging (20-40 frames, 20-40 msec duration each) was performed when the cell was in a down-state for at least $1.5 \mathrm{sec}$, to prevent the predepolarization effect that has been shown to affect the latency to first spike in spiny projection neurons (Mahon et al., 2000). This ensured that $\left[\mathrm{Ca}^{2+}\right]_{\mathrm{i}}$ transients from the previous up-state did not bias down-state measurements. After down-state fluorescence measurements, threshold crossing by a spontaneous up-state subsequently triggered up-state measurements. On average, 120-300 consecutive images (20-40 msec duration each, $380 \mathrm{~nm}$ ) were collected to measure a downstate and subsequent up-state. To exclude possible additive effects of $\left[\mathrm{Ca}^{2+}\right]_{\mathrm{i}}$ transients, up-states that occurred $<1.5 \mathrm{sec}$ after a preceding negative threshold-crossing were not included in the analysis.

Data are expressed as means \pm SE. For statistical data analysis, the Mann-Whitney nonparametric test was used unless stated otherwise (StatView; SAS Institute, Inc., Cary, NC).

\section{Results \\ Wide range of delays to first action potential during spontaneous up-states}

Spontaneous up-states were recorded from 30 striatal spiny projection neurons (Fig. 1A), and the time course and spatial distribution of somatic and dendritic $\left[\mathrm{Ca}^{2+}\right]_{\mathrm{i}}$ transients were simultaneously measured using fura-2 (Figs. $1 D, 2 B, E$ ). Up-states lasted $0.9 \pm 0.2 \mathrm{sec}$ on average and occurred irregularly at an average interval of $10.5 \pm 1.9 \mathrm{sec}(n=30$ neurons; 10 up-states per neuron). Readily noticeable during these spontaneous up-states were the highly variable time intervals between up-state onset and first action potential firing (Fig. $1 B$ ), which ranged from 5 to $\sim 600$ msec over the population (Fig. $1 C$ ) ( $n=87$ up-states from 30 neurons). The ranked distribution of up-states in Figure 1 revealed that up-states with only one action potential (filled triangle) did not rank differently with respect to latency to first spike 

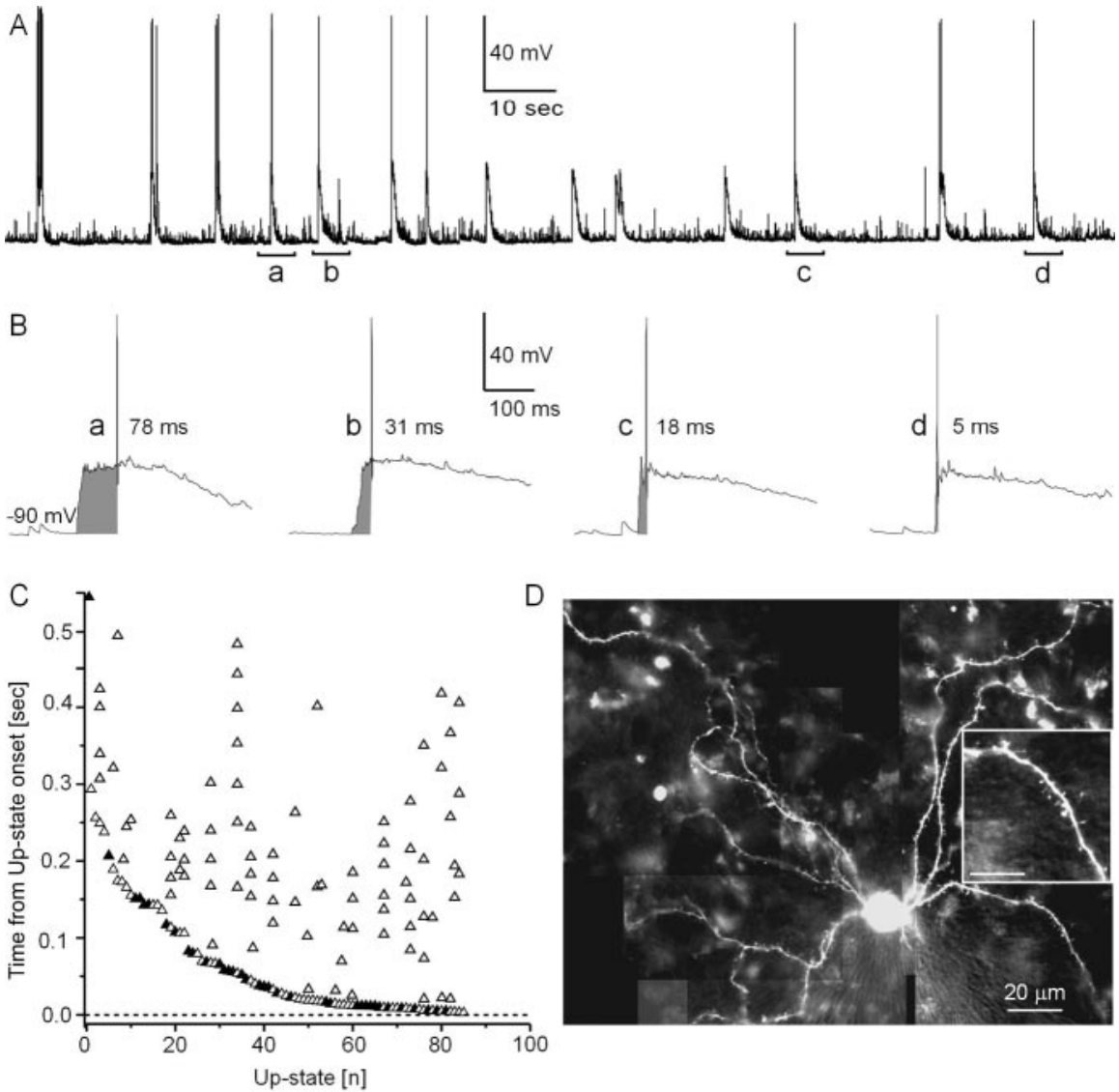

Figure 1. Spontaneous up-states in spiny projection neurons display a large variation in delay to first action potential with transitions to the up-state. $A$, Spontaneous subthreshold and suprathreshold up-states in a spiny projection neuron (whole-cell patch recording; cortex-striatum-substantia nigra organotypic coculture). Note fluctuations indicative of irregular spontaneous synaptic inputs during the down-state interrupted by large up-state depolarizations. $B$, Up-states in striatal spiny projection neurons are characterized by a fast transition from the down-state near resting potential to a subthreshold membrane potential range. Four individual up-states with variable delay to action potential firing relative to up-state onset are shown ( $a-d$, indicated in $A$ ). C, Timing of the first action potential relative to up-state onset ranked for a random selection of spontaneous up-states in decreasing order. Time delays cover a range of 5-600 msec across the population. Up-states with multiple action potentials (open triangles) display a similar range in delays to first action potential compared with up-states with only one action potential (filled triangles). In the present study, only up-states with one action potential were used for analysis. D, Fluorescence image $25 \mathrm{~min}$ after break-in at $380 \mathrm{~nm}$ (100 $\mu \mathrm{m}$ fura-2, 1 sec exposure, composite from 12 individual images). Scale bar, $20 \mu \mathrm{m}$. Note spines on dendrites (inset: scale bar, $10 \mu \mathrm{m}$ ).

onset when compared with up-states with multiple action potentials (open triangle). The distribution in delays also compares favorably with that reported in vivo (Mahon et al., 2001). Given that relative timing between synaptic inputs and somatic action potentials has been shown to control intracellular calcium in neurons during the down-state (Koester and Sakmann, 1998; Schiller et al., 1998), we assessed the correlation between transition into an up-state and action potential delay on dendritic $\left[\mathrm{Ca}^{2+}\right]_{\mathrm{i}}$ transients.

These data were extracted from peak $\Delta F / F$ differences $(\Delta F /$ $\left.F_{\max }\right)$ for dendritic $\left[\mathrm{Ca}^{2+}\right]_{\mathrm{i}}$ transients during up-states with just one spontaneous action potential. At the single neuron level, when comparing two separate up-states with a time to action potential of 10 and $88 \mathrm{msec}$, respectively (temporal difference of $78 \mathrm{msec}$ ) (Fig. $2 A, B$ ) there was a decrease by $50-100 \%$ in $\Delta F /$ $F_{\max }$ for the latter up-state. This occurred despite similar membrane potential distributions and action potential waveforms (Fig. 2C,D). Thus, the closer the spontaneous action potential was generated to the onset of the up-state, the greater the corresponding $\Delta F / F_{\max }$ value recorded at soma and dendrites.
This temporal relationship between action potential timing and $\Delta F / F_{\max }$ during up-states was also present at the population level (Fig. 2 F, 45 up-states with single action potential pooled). These population data revealed that $\Delta F / F_{\max }$ values were maximal between 10 and $20 \mathrm{msec}$ of up-state onset, at which time they were multiple times that of $\Delta F / F_{\max }$ values obtained for subthreshold up-states from the same group of neurons (Fig. $2 F$ ). $\Delta F / F_{\max }$ decayed quickly within $50-200 \mathrm{msec}$, at which time single action potentials did not elicit values significantly different from subthreshold up-states $(\Delta t=0-50 \mathrm{msec}$, $p<0.0001 ; \Delta t=150-200 \mathrm{msec}, p=0.63$; tertiary dendrite). The wide range of delays to spontaneous, single action potentials after up-state transitions (Fig. 1C) allowed us to obtain a timing function. A fit using a first-order exponential decay of this relationship revealed time constants of $52 \pm 15$ and $47 \pm 26 \mathrm{msec}$ for secondary and tertiary dendrites, respectively (Fig. $3 B)$. Such temporal dependence on intracellular calcium dynamics was only seen in suprathreshold up-states; in subthreshold up-states, average $\Delta F / F$ transients at soma and dendrites were highly correlated with average membrane potential trajectories (Fig. $3 A, C)\left(R^{2}=0.8-0.9\right.$; soma to tertiary dendrites). This suggests that the temporal dependency of $\Delta F / F_{\max }$ values in response to single action potentials could not have been predicted from the time course of synaptic activation during the up-state.

Together, this analysis demonstrated that timing of the first action potential during spontaneous up-states is highly predictive of elicited $\Delta F / F_{\max }$ transients, predominately in higher-order dendrites of spiny projection neurons.

Evoked action potentials at soma reproduce timing relationship in higher-order dendrites

If the delay between action potential firing and up-state onset is the main determinant for the changes in $\Delta F / F_{\max }$ described in the previous section, then action potentials evoked by somatic current injection during subthreshold up-states should reveal a similar functional relationship. Briefly, suprathreshold somatic current pulses were injected at various times after up-state onset (Fig. $4 A$ ), and the resulting $\Delta F / F_{\max }$ values were obtained for all compartments. Only up-states with a single action potential evoked through somatic current injection were chosen for this analysis.

As described for up-states with spontaneous action potentials, evoked action potentials elicited greater $\Delta F / F_{\max }$ values in both soma and dendrites, the closer they were elicited to up-state onset (Fig. $4 A, B$ ). This timing relationship held true for $\Delta F / F_{\max }$ values at the single-neuron level (Fig. $4 A, B$ ), as well as for the population of neurons (Fig. $4 C)(n=12$ neurons). There were no differences between action potential waveforms at different injec- 


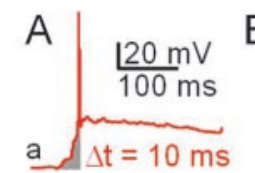

\section{"}
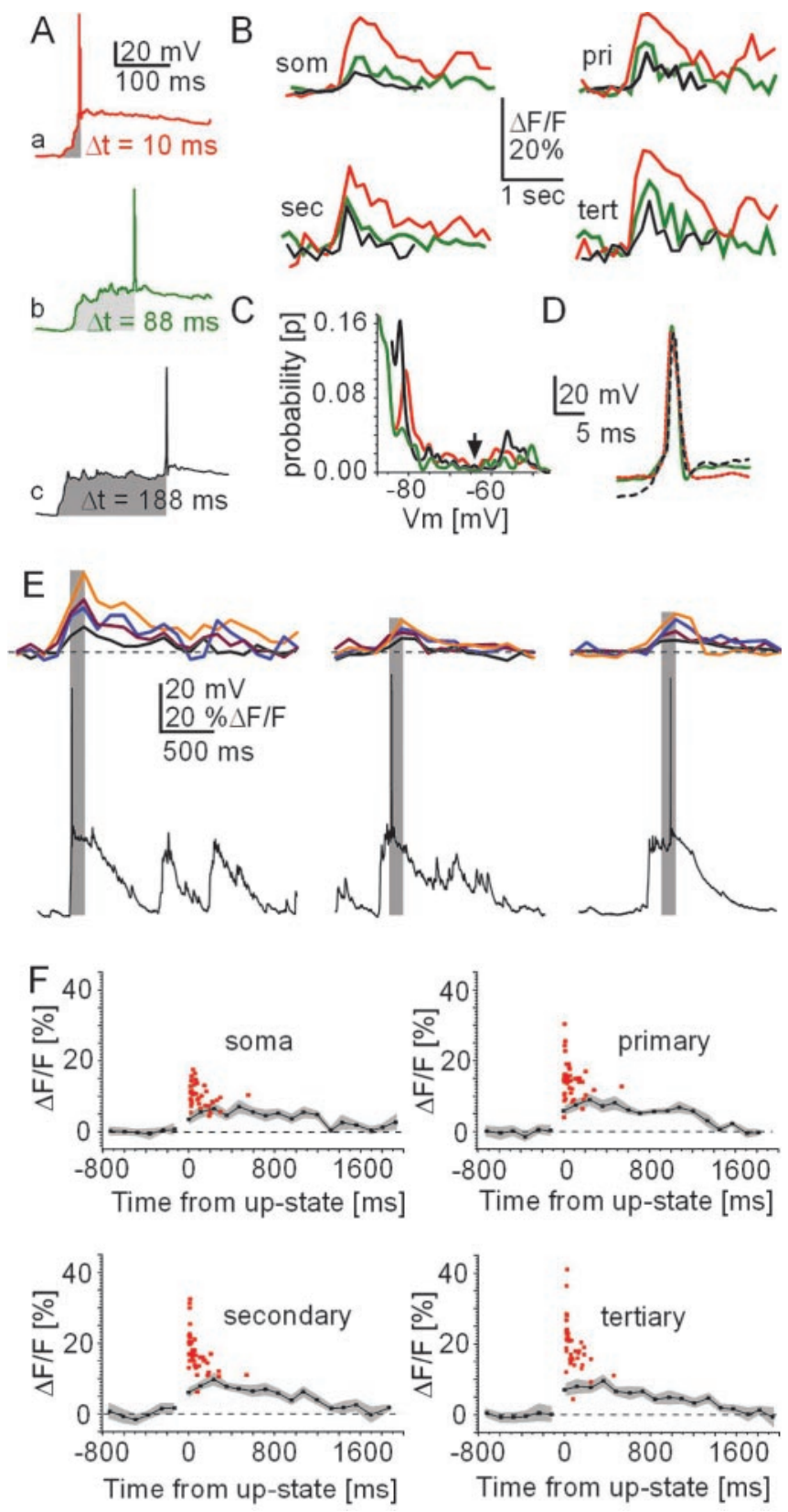

Figure 2. Timing dependency of $\Delta F / F_{\max }$ for action potential firing relative to up-state onset. $A$, Spontaneous up-states and corresponding $\left[\mathrm{Ca}^{2+}\right]_{\mathrm{i}}$ transients $(B)$ at soma and dendrites for different delays to action potential firing with up-state onset ( $\Delta t$, shaded gray). Each trace is a single sweep collected at $380 \mathrm{~nm}$ wavelength ( $\Delta 39 \mathrm{msec}$ each) allowing a background-corrected calculation of $\Delta F / F$ values. som, Soma; pri, primary; sec, secondary; tert, tertiary. $C, D$, Corresponding bimodal membrane potential distribution and action potential waveform shown for each up-state in $A . E$, Peak $\left[\mathrm{Ca}^{2+}\right]_{\mathrm{i}}$ transients are temporally aligned with action potential firing. Three single action potential up-states with corresponding calcium transients from soma (black), as well as primary (dark red), secondary (blue), and tertiary (orange) are shown. Each peak $\left[\mathrm{Ca}^{2+}\right]_{\mathrm{i}}$ transient was in the same frame (gray shading) as the action potential. $F, \Delta F / F_{\max }$ values from spontaneous up-states with one action potential (red squares) are overlaid on averaged $\left[\mathrm{Ca}^{2+}\right]_{\mathrm{i}}$ transients for subthreshold up-states from the same population of neurons. Zero indicates up-state onset. SE is indicated in gray.

tion times (data not shown). The $\Delta F / F_{\max }$ values for evoked action potentials displayed the same timing relationship as spontaneous action potentials and were not significantly different (see Fig. 6, $0-50$ msec; $p=0.7-0.9$; soma to tertiary dendrite). No significant differences were found between subthreshold up-state
$\Delta F / F_{\max }$ values for both conditions, and data from subthreshold up-states were pooled from both groups. These experiments expanded on our previous finding that somatic action potentials propagate into the higher-order dendrites of spiny projection neurons during up-states (Kerr and Plenz, 2002) and introduce timing with respect to up-state onset as an important variable that controls dendritic $\left[\mathrm{Ca}^{2+}\right]_{\mathrm{i}}$.

\section{Timing mechanism related to NMDA receptor activation}

In the presence of relatively few synaptic inputs, previous work in cortical pyramidal neurons established an NMDA-dependent temporal relationship between synaptic activation and backpropagating action potentials, which describes dendritic $\left[\mathrm{Ca}^{2+}\right]_{\mathrm{i}}$ transients (Koester and Sakmann, 1998; Schiller et al., 1998). We hypothesized that the NMDA receptor might also account for the temporal dependence of dendritic $\left[\mathrm{Ca}^{2+}\right]_{\mathrm{i}}$ described here during the up-state. Because up-state generation requires activation of the neuronal network, we had to refer to a method that would allow NMDA receptor manipulation without affecting the surrounding network. This was achieved using a high internal magnesium concentration $\left(\left[\mathrm{Mg}^{2+}\right]_{\mathrm{i}}\right)$ inside the patch pipette to selectively block the NMDA receptor channels from the neuron from which recorded (Li-Smerin and Johnson, 1996; Wollmuth et al., 1998; Li-Smerin et al., 2001).

Under conditions of high $\left[\mathrm{Mg}^{2+}\right]_{\mathrm{i}}$, the temporal dependency that was observed during up-states between backpropagating action potentials and up-state onset was completely abolished (Figs. 5, 6). At the single neuron level, there was no difference in $\Delta F / F_{\max }$ values between up-states in which the action potential occurred 10, 88, or $288 \mathrm{msec}$ after up-state onset (Fig. 5A,B). More specifically, $\Delta F / F_{\max }$ values for both spontaneous and evoked up-states were significantly decreased for up to $100 \mathrm{msec}$ after up-state onset, effectively abolishing the timing relationship (Fig. $5 C)(n=6$ neurons; $p=0.002-0.0001$; soma to tertiary dendrite).

This effect of high $\left[\mathrm{Mg}^{2+}\right]_{\mathrm{i}}$ was not attributable to nonspecific actions on the intrinsic electrophysiological properties of the recorded neurons. First, up-states of neurons recorded with high $\left[\mathrm{Mg}^{2+}\right]_{\mathrm{i}}$ were not significantly different from neurons recorded under control conditions [resting membrane potential for controls, $-82.4 \pm 0.8 \mathrm{mV}(n=20)$; resting membrane potential for high $\left.\left[\mathrm{Mg}^{2+}\right]_{\mathrm{i}},-81.6 \pm 0.4 \mathrm{mV}(n=6) ; p=0.43\right]$. The up-state duration for controls was $0.9 \pm 0.2 \mathrm{sec}$, compared with $0.75 \pm$ 0.032 for high $\left[\mathrm{Mg}^{2+}\right]_{\mathrm{i}}(p=0.56)$. The number of action potentials during up-states for controls was $3.2 \pm 0.2$, compared with $2.9 \pm 0.2$ for high $\left[\mathrm{Mg}^{2+}\right]_{\mathrm{i}}(p=0.34)$. Second, action potential waveforms were not different between both conditions (Fig. 5D) (half width: $1.1 \pm 0.1 \mathrm{msec}$ for controls, $1.2 \pm 0.1 \mathrm{msec}$ at high $\left[\mathrm{Mg}^{2+}\right]_{\mathrm{i}}, p=0.19$; amplitude: $76 \pm 7 \mathrm{mV}$ for controls, $78 \pm 9 \mathrm{mV}$ at high $\left.\left[\mathrm{Mg}^{2+}\right]_{\mathrm{i}}, p=0.91 ; n=20\right)$. Third, high $\left[\mathrm{Mg}^{2+}\right]_{\mathrm{i}}$ reduced $\Delta F / F$ values in subthreshold up-states slightly but not significantly compared with controls (Figs. $2 E, 5 C$ ). These results demonstrate that the described dependency of dendritic $\left[\mathrm{Ca}^{2+}\right]_{\mathrm{i}}$ peaks on action potential timing during up-states is sensitive to high $\left[\mathrm{Mg}^{2+}\right]_{\mathrm{i}}$.

\section{Coincidence of NMDA receptor activation and}

backpropagating action potentials triggers dendritic $\left[\mathrm{Ca}^{2+}\right]_{\mathrm{i}}$ transients in spiny projection neurons

A high $\left[\mathrm{Mg}^{2+}\right]_{\mathrm{i}}$ of $10 \mathrm{~mm}$ has been demonstrated to block somatic NMDA channel currents at $>0 \mathrm{mV}$ membrane potential depolarization (Li-Smerin and Johnson, 1996; Wollmuth et al., 1998; Li-Smerin et al., 2001). We hypothesized that the voltage- 

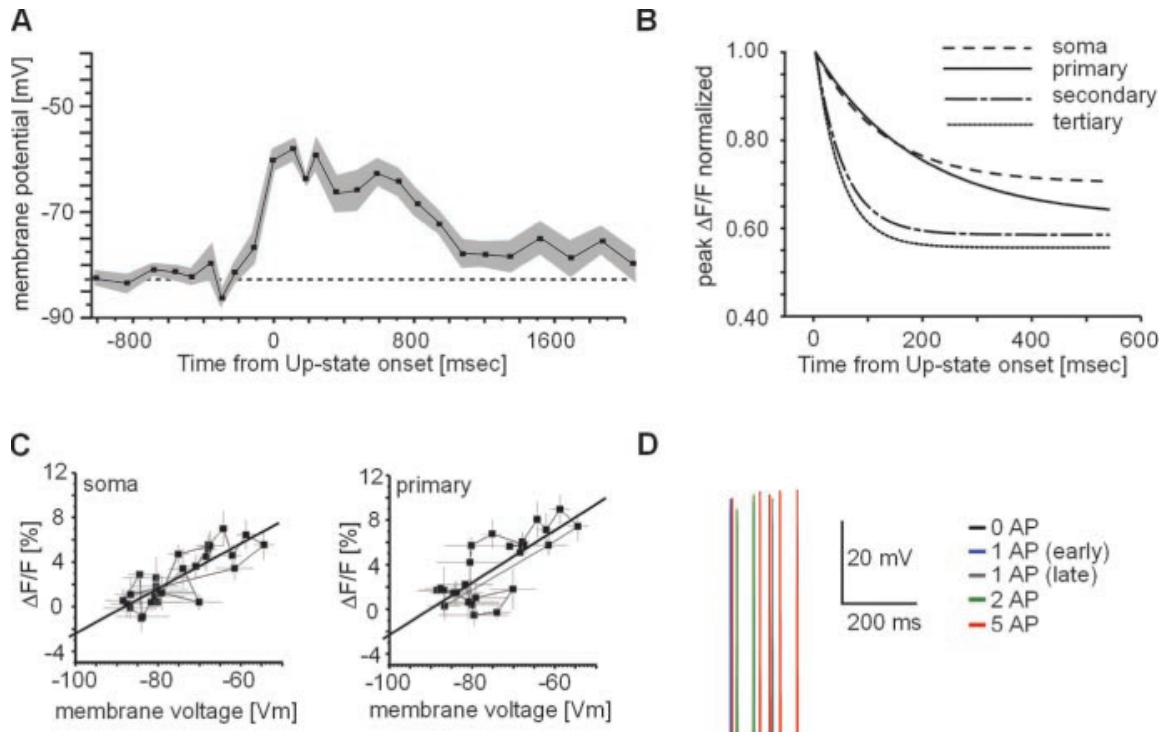

D
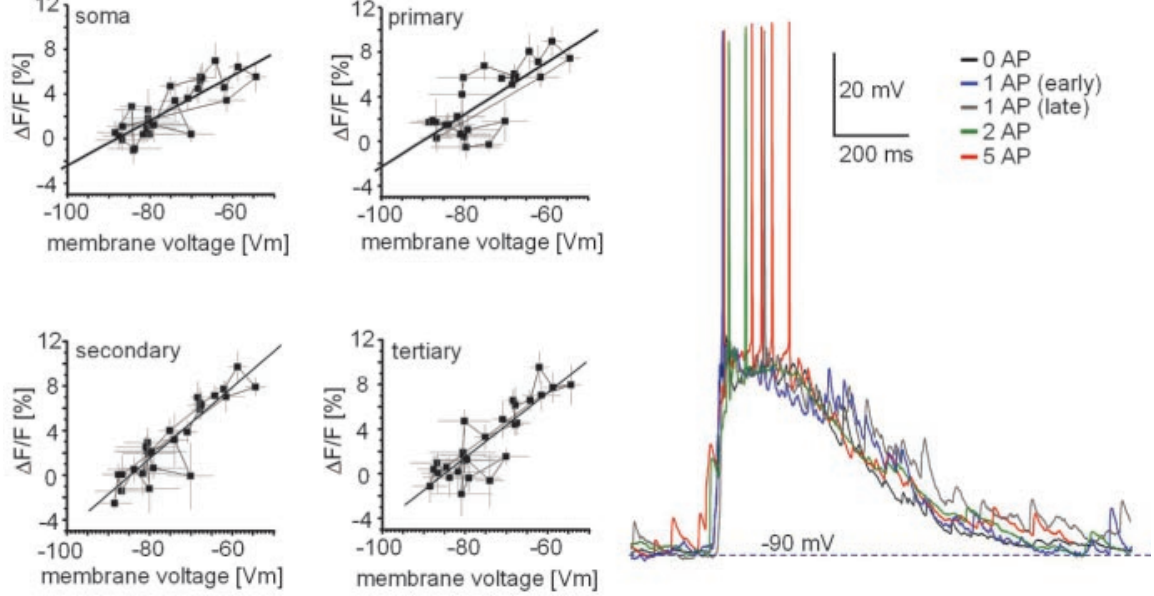

Figure 3. Somatic membrane potential trajectories during up- and down-states are highly correlated with somatic and dendritic $\left[\mathrm{Ca}^{2+}\right]_{\mathrm{i}}$ transients. A, Average subthreshold up-state membrane potential time course for all up-states analyzed. Membrane potential values reflect averages, down-sampled to imaging frame rate (39 msec; SE in gray). $B$, Timing relationship is more pronounced in higher-order dendrites (first-order exponential decay for data shown in Fig. 2 F). C, Correlation between up- and down-state transitions of somatic membrane potential trajectory and $\Delta F / F$ values over time at soma and dendrites (solid line indicates linear regression; subthreshold up-states from $n=15$ neurons). $D$, Membrane potential trajectory is similar for upstates with different numbers of action potentials (AP). An overlay of voltage traces for four suprathreshold up-states and one subthreshold up-state is shown.

dependent action of high $\left[\mathrm{Mg}^{2+}\right]_{\mathrm{i}}$ also selectively affects dendritic $\left[\mathrm{Ca}^{2+}\right]_{\mathrm{i}}$ transients in higher-order dendrites of spiny projection neurons and might be responsible for blocking calcium entry via the NMDA receptor, triggered by a backpropagating action potential. First, in the presence of DNQX $(30 \mu \mathrm{M})$ local pressure application of NMDA alone resulted in a somatic membrane potential depolarization that lasted for 3-4 sec. This depolarization was accompanied by somatic and dendritic $\left[\mathrm{Ca}^{2+}\right]_{\mathrm{i}}$ transients of similar time course, which reached $3-7 \% \Delta F / F_{\max }$ ( $n=10$ neurons) (Figs. 7A, $B, 8 \mathrm{~A}$, soma to higher-order dendrites). Under conditions of high $\left[\mathrm{Mg}^{2+}\right]_{\mathrm{i}}$, dendritic $\Delta F / F$ transients in response to NMDA application alone were not different in amplitude and time course compared with control conditions (Fig. $7 B)$ ( $p=0.68-0.76$; soma to tertiary dendrite). In contrast, three somatic action potentials elicited fast $\Delta F / F$ transients at soma and dendrites that reached $7-14 \% \Delta F / F_{\max }$ under control conditions (Figs. $7 A, B, 8 B$ ) but were significantly reduced in dendrites in the presence of high $\left[\mathrm{Mg}^{2+}\right]_{\mathrm{i}}$ (Figs. 7, $\left.8 B\right)(p=$ $0.009-0.007$; primary to tertiary dendrite). Finally, when local NMDA application was combined with evoked somatic action potentials, fast $\Delta F / F$ transients up to $24 \% \Delta F / F_{\max }$ were obtained under control conditions, whereas these $\Delta F / F_{\max }$ values were highly reduced in dendrites in the presence of high $\left[\mathrm{Mg}^{2+}\right]$ (Figs. $7,8 C)(p=0.007-0.0001$; primary to tertiary dendrite). This reduction in the combined case reached up to $55 \%$ (e.g., tertiary dendrite) (Fig. 8) and could not be explained by the reduction seen in response to evoked action potentials only. No significant effects of high $\left[\mathrm{Mg}^{2+}\right]_{\mathrm{i}}$ were found on somatic $\Delta F / F$ values ( $p=0.32$, NMDA only; $p=0.11$, three action potentials).

Several important controls were conducted to test for the selective involvement of NMDA receptor function in these results. First, to ensure that the induced somatic membrane potential depolarization and $\left[\mathrm{Ca}^{2+}\right]_{\mathrm{i}}$ transients were not biased by pressure injection artifacts, we demonstrated that both components were blocked by bath application of the NMDA receptor antagonist APV $(30 \mu \mathrm{M})$ (Fig. $7 E$ ). Second, to demonstrate that high $\left[\mathrm{Mg}^{2+}\right]_{\mathrm{i}}$ was blocking the NMDA channel, we bath-applied APV $(30 \mu \mathrm{M})$ while eliciting action potentials in the presence of high $\left[\mathrm{Mg}^{2+}\right]_{\mathrm{i}}$. Because backpropagating action potentials alone elicit dendritic $\left[\mathrm{Ca}^{2+}\right]_{\mathrm{i}}$ influx through the NMDA channel (Schiller et al., 1998; Yuste et al., 1999), if high $\left[\mathrm{Mg}^{2+}\right]_{\mathrm{i}}$ was not blocking the NMDA channel, then we would expect application of APV to further decrease $\left[\mathrm{Ca}^{2+}\right]_{\mathrm{i}}$ transients brought about by backpropagating action potentials into the dendrites. However, this was not the case, suggesting that high $\left[\mathrm{Mg}^{2+}\right]_{\mathrm{i}}$ blocks NMDA channels in higher-order dendrites of spiny projection neurons (Fig. $8 B)(p=0.45-0.12$; soma to tertiary dendrite).

Together these experiments show that high $\left[\mathrm{Mg}^{2+}\right]_{\mathrm{i}}$ selectively blocks the NMDA channel contribution to dendritic $\mathrm{Ca}^{2+}$ influx elicited by backpropagating action potentials in striatal spiny projection neurons. We therefore conclude that the dependence of dendritic $\left[\mathrm{Ca}^{2+}\right]_{\mathrm{i}}$ on the delay between up-state onset and action potential generation results from temporal dynamics of NMDA receptor activation during up-states.

\section{Discussion}

The current study introduces a timing function that determines dendritic $\left[\mathrm{Ca}^{2+}\right]_{\mathrm{i}}$ levels during up-states. With a transition into the up-state, the subsequent delay to firing an action potential determines the increase in $\left[\mathrm{Ca}^{2+}\right]_{\mathrm{i}}$ in higher-order dendrites. This increase in dendritic $\left[\mathrm{Ca}^{2+}\right]_{\mathrm{i}}$ depends on the interaction between the backpropagated action potential and NMDA receptors during the up-state.

Our results tie together two characteristic aspects of striatal neuronal activity that have been reported in many studies over the last few decades. At the intracellular level, a large depolarization into a subthreshold membrane potential range, the up-state, has been described by Wilson and colleagues (Wilson and Kawaguchi, 1996; Stern et al., 1997) and reflects how striatal spiny projection neurons operate in the context of corticostriatal inputs. These synaptically driven, prominent up-state transitions are contrasted by relatively sparse action potential firing during the up-state, which is in accordance with findings from extracel- 


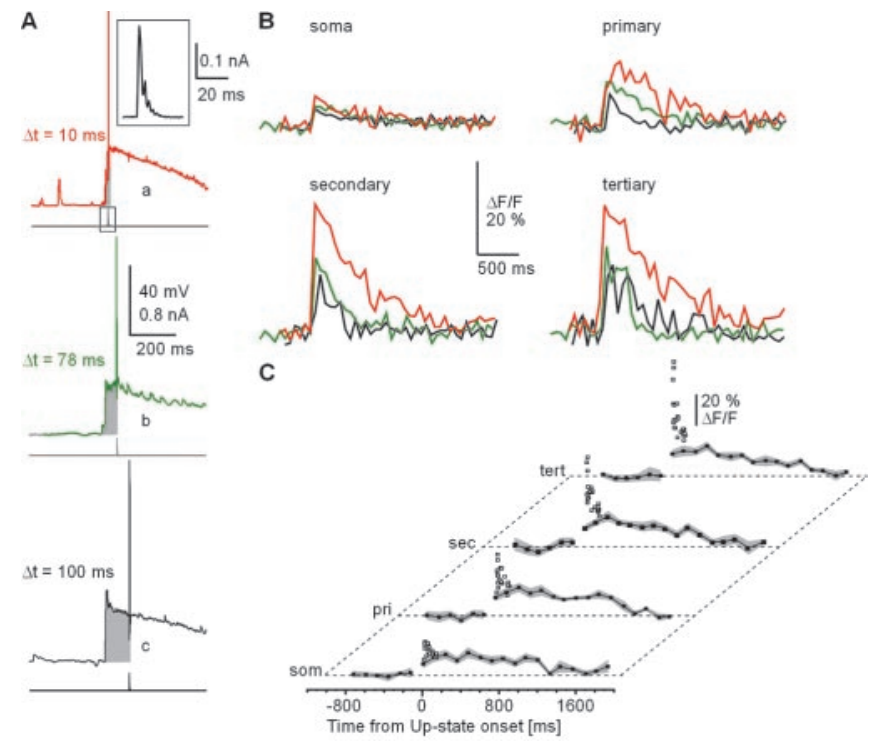

Figure 4. Time dependency of $\left[\mathrm{Ca}^{2+}\right]_{\mathrm{i}}$ transients replicated by evoked action potentials during up-states. $A$, Single up-states with action potential evoked by somatic current injection at various times from up-state onset. Top trace, Voltage trace of first $500 \mathrm{msec}$ of spontaneous subthreshold up-states with evoked action potential. Bottom trace, Timing and amplitude of somatic current injection. Inset, Exponentially decaying current pulse used to precisely time a single evoked action potential during the up-state. $B$, Corresponding $\left[\mathrm{Ca}^{2+}\right]_{\mathrm{i}}$ transients overplotted for up-states in $A$. C, Population summary of $\Delta F / F_{\max }$ values for up-states with evoked single action potentials (open squares). som, Soma; pri, primary; sec, secondary; tert, tertiary. The average $\Delta F / F$ time course for subthreshold up-states from the same population of neurons is shown (SE in gray, as in Fig. 2F).

lular studies in vivo (Hikosaka et al., 1989b; Jog et al., 1999). Whereas many studies on striatal function focus on the role of action potential bursts and firing rate changes (Schultz and Romo, 1988; Hikosaka et al., 1989a; Jog et al., 1999), our findings suggest that spiny projection neurons, through $\left[\mathrm{Ca}^{2+}\right]_{\mathrm{i}}$ transients, regulate their activity based on a temporally precise mechanism already at the level of single action potentials.

The temporal precision of the resulting parametric function depends on a multitude of factors. First, threshold for up-state detection was derived statistically from down-state activity, which introduces a jitter for up-state determination of $\sim 10 \mathrm{msec}$. Our temporal resolution for imaging of 20-40 msec per frame averages $\left[\mathrm{Ca}^{2+}\right]_{\mathrm{i}}$ transients, thereby reducing fast-peak $\Delta F / F$ values. Similarly, fura-2 acts as a $\left[\mathrm{Ca}^{2+}\right]_{\mathrm{i}}$ buffer (Helmchen et al., 1996), also reducing fast $\left[\mathrm{Ca}^{2+}\right]_{i}$ transients. Spatial averaging that includes large regions of the dendrite such as the spiny head, necks, and dendritic shafts will also reduce fast $\left[\mathrm{Ca}^{2+}\right]_{\mathrm{i}}$ transients (Denk et al., 1996). Therefore, reported $\Delta F / F$ transients in the present study most likely underestimate actual fast changes in dendritic $\left[\mathrm{Ca}^{2+}\right]_{\mathrm{i}}$, and the time constants of 40-50 msec reported here should be taken as upper boundaries for temporal precision.

\section{Regulation of action potential timing in spiny projection neurons}

A delay in action potential firing in response to depolarizing somatic current injection is a hallmark for spiny projection neurons. This characteristic delay is controlled by several inwardly rectifying potassium currents (Surmeier et al., 1989; Nisenbaum and Wilson, 1995) that activate with depolarization from rest and increase the time to reach action potential threshold. A fast and a slow transient potassium current (Nisenbaum and Wilson, 1995) were reported that, together with a noninactivating and/or slowly

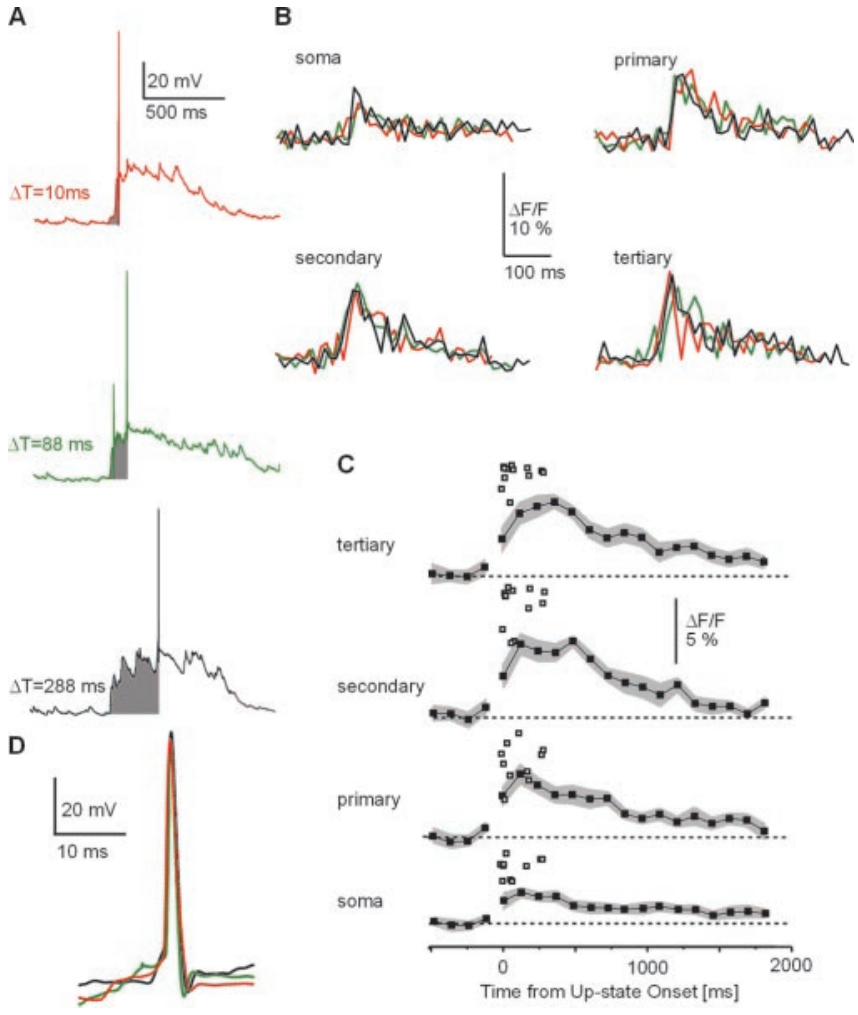

Figure 5. High $\left[\mathrm{Mg}^{2+}\right]_{i}$ abolishes the dependency of peak dendritic $\left[\mathrm{Ca}^{2+}\right]_{i}$ transients on time between up-state onset and action potential firing. $A$, Spontaneous up-states in the presence of high $\left[\mathrm{Mg}^{2+}\right]_{\mathrm{i}}$ and corresponding $\Delta F / F$ transients $(B)$ in striatal spiny projection neurons. Times from up-state onset to action potential firing (shaded gray) are denoted in milliseconds. Note that $\Delta F / F$ transients are similar for each region and independent of the time of action potential occurrence (single-sweep $\Delta F / F$ transients at $380 \mathrm{~nm}$, at a 39 msec frame rate). $C, \Delta F / F_{\max }$ values for single action potentials during up-states under conditions of high $\left[\mathrm{Mg}^{2+}\right]_{\mathrm{i}}$. An average $\Delta F / F$ time course for subthreshold up-states is shown (filled squares, $S E$ in gray). Despite varied action potential timing in relation to up-state onset, there is little correlation to peak $\Delta F / F$. Note smaller $\Delta F / F$ scale compared with Figure $2 F$. D, Action potentials from each up-state in $A$ are overlaid, showing very similar action potential waveforms.

inactivating potassium current (Nisenbaum et al., 1994), cover the temporal scale of 10 to $\sim 500 \mathrm{msec}$ in spiny projection neurons. These currents are modulated by acetylcholine (Akins et al., 1990) and dopamine (Surmeier and Kitai, 1993), neuromodulators central to striatal function. These potassium channels are also activated on a transition to the up-state, where they contribute to delayed action potential firing (Wilson and Kawaguchi, 1996; Kitano et al., 2002). Our results suggest a new context in which these elaborate intrinsic mechanisms to delay action potential firing can be interpreted: delays can be directly translated into dramatic changes in dendritic $\left[\mathrm{Ca}^{2+}\right]_{\mathrm{i}}$ transients in higherorder dendrites.

Similarly, $>98 \%$ of striatal neurons are GABAergic (Oorschot, 1996). The impact of GABAergic input to spiny projection neurons has been suggested to delay action potential firing rather than blocking action potentials altogether (for review, see Plenz, 2003). Both feedforward inhibition from GABAergic fast-spiking interneurons (Plenz and Kitai, 1998; Koos and Tepper, 1999) and feedback inhibition from surrounding GABAergic spiny projection neurons (Czubayko and Plenz, 2002; Tunstall et al., 2002) are likely to control action potential timing during the up-state. Our results suggest that intrinsic mechanisms and synaptic inputs from the local network, through control of action potential timing, regulate dendritic $\left[\mathrm{Ca}^{2+}\right]_{i}$ at a precise temporal scale in spiny projection neurons. 

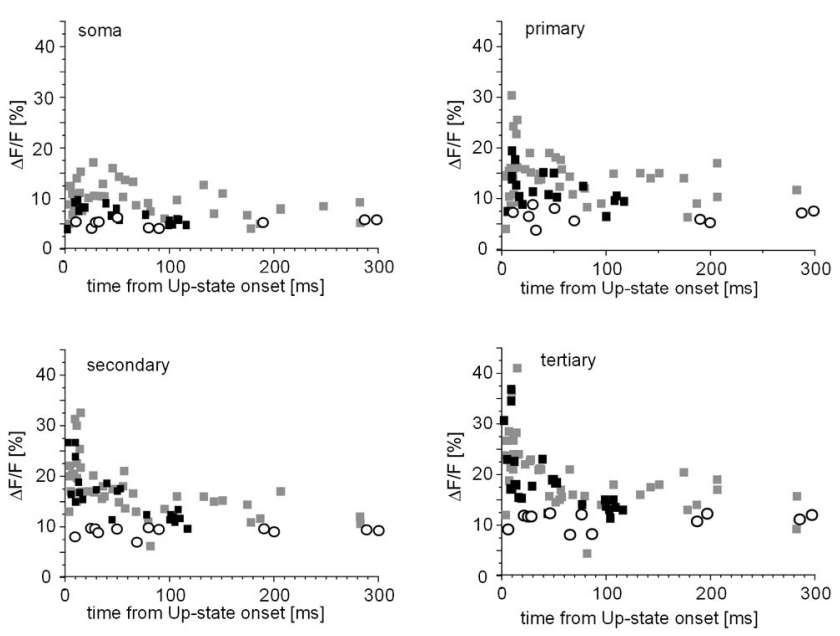

Figure 6. The time dependency of $\left[\mathrm{Ca}^{2+}\right]_{\mathrm{i}}$ during up-states is similar for spontaneous and evoked action potentials and is abolished in the presence of high $\left[\mathrm{Mg}^{2+}\right]_{\mathrm{i}}$. A summary plot at high resolution of $\Delta F / F_{\max }$ values from up-states with a single, spontaneous action potential (gray squares, Fig. 2F), a single, evoked action potential (black squares, Fig. 4C), and single action potential up-states in the presence of high $\left[\mathrm{Mg}^{2+}\right]_{\mathrm{i}}$ (open circles, Fig. 5 () is shown. Note that single action potentials, whether spontaneous or evoked, result in a similar time dependency for $\Delta F / F_{\text {max }}$, especially in secondary and tertiary dendrites.

\section{NMDA receptor function in spiny projection neurons}

The present study demonstrates for the first time that NMDA receptor activation is involved in calcium entry to the dendrites in spiny projection neurons. NMDA receptors have been located at postsynaptic sites in spiny projection neuron dendrites that receive corticostriatal inputs (Wang and Pickel, 2000). Striatal spiny projections neurons possess all major NMDA subunits, including NMDA subunit NR1, NR2A, and/or NR2B (Standaert et al., 1999; Dunah and Standaert, 2003), that are known to be involved in regulation of intracellular calcium during the coincidence of synaptic activity and backpropagating action potentials in pyramidal neurons (Schiller et al., 1998; Yuste et al., 1999). Functionally, local NMDA application strongly depolarizes striatal spiny projection neurons (Cepeda and Levine, 1998) and in addition, NMDA receptor activation is important for the induction of corticostriatal long-term potentiation (Calabresi et al., 1992b).

The use of high concentrations of intracellular $\mathrm{Mg}^{2+}$ preferentially blocks NMDA channel currents, mainly above $0 \mathrm{mV}$ membrane potential in cultured pyramidal neurons (Li-Smerin and Johnson, 1996; Li-Smerin et al., 2001) and in oocytes (Wollmuth et al., 1998). Our results suggest that a similar selectivity of the high $\left[\mathrm{Mg}^{2+}\right]_{\mathrm{i}}$ block is present in intact spiny projection neurons, because increasing $\left[\mathrm{Mg}^{2+}\right]_{\mathrm{i}}$ did not affect subthreshold responses to local NMDA application but did affect dendritic response to depolarizations of $>0 \mathrm{mV}$. Moreover, high $\left[\mathrm{Mg}^{2+}\right]_{\mathrm{i}}$ significantly reduced dendritic $\left[\mathrm{Ca}^{2+}\right]_{\mathrm{i}}$ transients induced by combining somatic action potentials with local NMDA application. Although these experiments did not directly test the function of $\left[\mathrm{Mg}^{2+}\right]_{\mathrm{i}}$ in these cells, reduction of the NMDA response under high $\left[\mathrm{Mg}^{2+}\right]_{i}$ was not further affected by the application of an NMDA receptor-specific antagonist. Thus, the current study demonstrates for the first time a highly significant interaction between NMDA receptor activation and somatic action potential firing that controls dendritic $\left[\mathrm{Ca}^{2+}\right]_{\mathrm{i}}$ levels in striatal spiny projection neurons.

The time dependency of intracellular $\left[\mathrm{Ca}^{2+}\right]_{\mathrm{i}}$ transients elic-

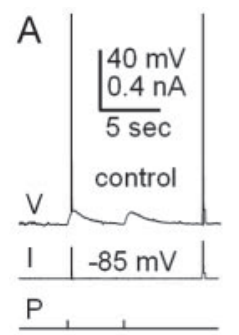

B

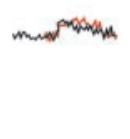

NMDA application
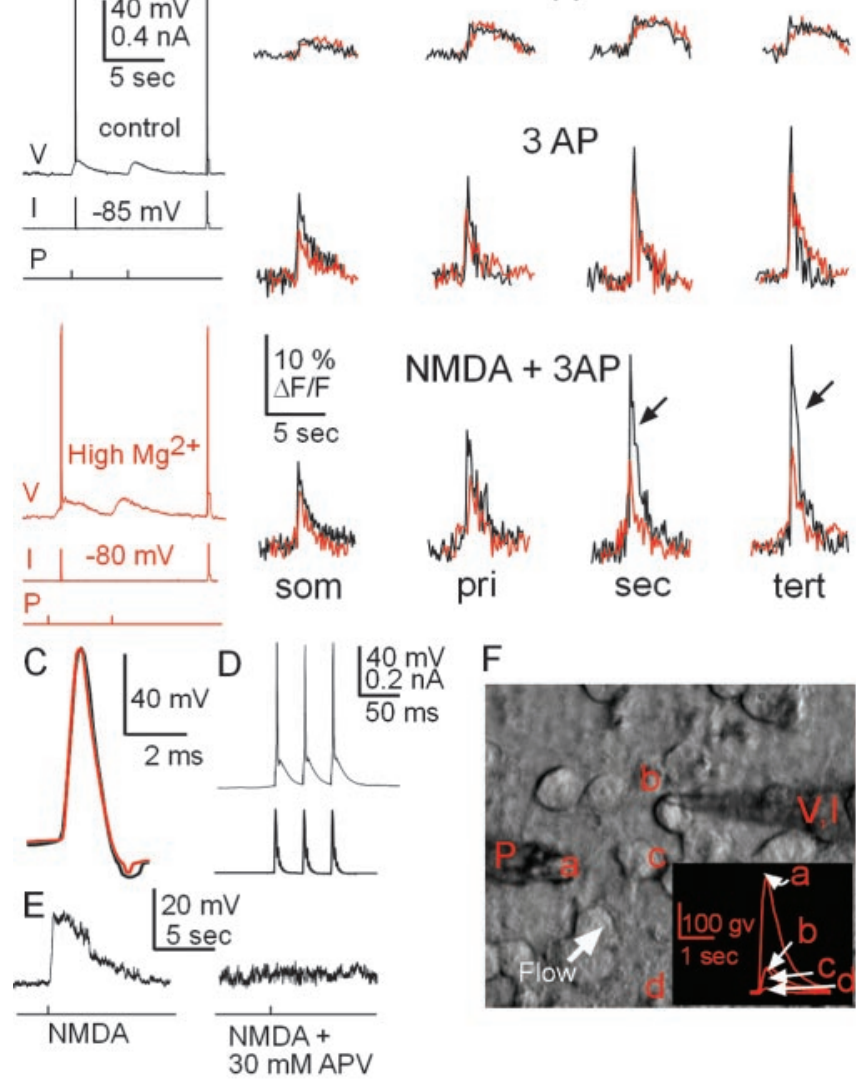

Figure 7. Backpropagating action potentials that coincide with local NMDA application elicit dendritic $\left[\mathrm{Ca}^{2+}\right]_{\mathrm{i}}$ transients that are drastically reduced in the presence of high $\left[\mathrm{Mg}^{2+}\right]_{\mathrm{i}} \cdot A$, Membrane potential $(V)$, current $(I)$, and pressure $(P)$ time traces under normal conditions (top traces) and high $\left[\mathrm{Mg}^{2+}\right]_{\mathrm{i}}$ (bottom traces, red). Temporal order is as follows: (1) Three evoked action potentials in conjunction with locally applied NMDA, (2) NMDA pressure application only, and (3) three evoked action potentials only. B, Corresponding single-sweep measurement of $\left[\mathrm{Ca}^{2+}\right]_{\mathrm{i}}$ transients in soma and dendrites during pressure application of NMDA (top), three evoked action potentials (AP; middle), and combination of both local NMDA application and three evoked action potentials (bottom). Corresponding traces for controls (black) and high $\left[\mathrm{Mg}^{2+}\right]_{\mathrm{i}}$ (red) are overlaid (from different spiny projection neurons). Note that high $\left[\mathrm{Mg}^{2+}\right]_{\mathrm{i}}$ significantly reduces $\left[\mathrm{Ca}^{2+}\right]_{\mathrm{i}}$ transients from action potentials alone and in combination with NMDA application (arrows). High $\left[\mathrm{Mg}^{2+}\right]_{i}$ has no effect on $\left[\mathrm{Ca}^{2+}\right]_{i}$ transients from subthreshold NMDA application. som, Soma; pri, primary; sec, secondary; tert, tertiary. C, Enlarged time view of action potential waveform from controls (black) overlaid with action potential with high $\left[\mathrm{Mg}^{2+}\right]_{\mathrm{i}}(\mathrm{red})$. D, Somatic current injection (bottom trace) reliably elicited three action potentials (top trace). E, Bath addition of APV $(30 \mu \mathrm{m})$ blocked the somatic membrane potential depolarization in response to brief NMDA (10 msec, $30 \mu \mathrm{m}$ DNQX present throughout the experiment). $F$, Light transmission image showing a patch pipette $(V, I)$ attached to the soma of a spiny projection neuron $(b)$ and an NMDA pressure application pipette $(P)$. The white arrow depicts the direction of ACSF flow over the entire culture, and the inset depicts relative concentration gradient of dye ejected from pipette at pipette tip (a), neuron soma $(b)$, area over dendrites $(c)$, and $60 \mu \mathrm{m}$ from soma (d) (all values are expressed in gray values with background subtraction).

ited through backpropagating action potentials was completely abolished by blocking NMDA channels internally. Furthermore, we were able to reproduce this timing dependency by evoking action potentials at the soma. These findings strongly imply that with transition to the up-state, the population of activated NMDA receptors that interact with backpropagating somatic action potentials is a key factor that determines this timing function. Because the spatiotemporal characteristics of synaptic inputs for up-state generation are currently unknown, two scenarios will be outlined. In its simplest form, glutamatergic 
A

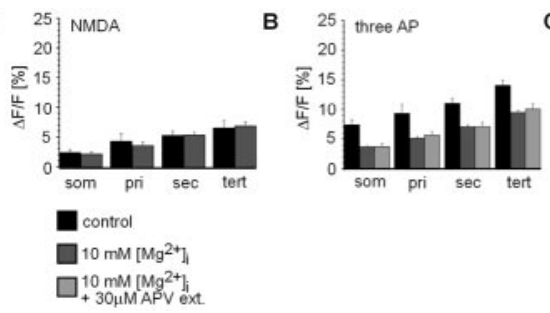

Figure 8. Supralinear dendritic $\left[\mathrm{Ca}^{2+}\right]_{\mathrm{i}}$ transients are blocked by high $\left[\mathrm{Mg}^{2+}\right]_{\mathrm{i}}$ through the NMDA receptor complex. $A, \Delta F / F_{\text {max }}$ values from local NMDA application are not significantly different for controls and high $\left[\mathrm{Mg}^{2+}\right]_{\mathrm{i}}$. B, High $\left[\mathrm{Mg}^{2+}\right]_{\mathrm{i}}$ significantly reduces calcium influx through the NMDA receptor in response to backpropagating action potentials (AP). $\Delta F / F_{\max }$ values in response to three somatically induced action potentials under normal conditions, in the presence of high $\left[\mathrm{Mg}^{2+}\right]_{i}$, and in the presence of high internal $\left[\mathrm{Mg}^{2+}\right]_{i}$ with the externally applied NMDA receptor antagonist APV (APV ext.) are shown. C, High $\left[\mathrm{Mg}^{2+}\right]_{i}$ significantly reduces $\Delta F / F_{\max }$ values that result from the combination of three somatically induced action potentials and local NMDA application. som, Soma; pri, primary; sec, secondary; tert, tertiary.

inputs could synchronously activate NMDA receptors at the upstate onset. In this case, the timing function would be dominated by the average deactivation of this receptor population (Gotz et al., 1997). Alternatively, the average number of activated NMDA receptors by synaptic inputs might decrease as the up-state progresses. In the latter case, the timing function would reflect the decrease in the number of NMDA receptors activated during the up-state.

\section{Precisely timed action potentials during up-states and their relevance to corticostriatal plasticity}

The cortex is the main source for glutamatergic inputs that drive striatal spiny projection neurons into the up-state. These corticostriatal inputs are highly plastic and exhibit long-term depression (Calabresi et al., 1992a; Lovinger et al., 1993) as well as long-term facilitation (Kerr and Wickens, 2001; Reynolds et al., 2001). In pyramidal neurons during low levels of synaptic activity, single action potentials precisely timed to coincide with synaptic inputs critically regulate dendritic calcium levels (Koester and Sakmann, 1998) and synaptic plasticity (Magee and Johnston, 1997; Markram et al., 1997; for review, see Stuart and Hausser, 2001). These findings have established timing rules that link the delay between a backpropagating somatic action potential and few synaptic inputs to the direction of synaptic change (Bi and Poo, 1998). Whether these findings on spike-timedependent plasticity can be extended to up-states is currently not known, because up-states present an entirely different set of parameters compared with periods of little synaptic activity (Waters et al., 2003). During an up-state, there is a dramatically reduced neuronal input resistance (Wilson and Kawaguchi, 1996) and a high level of synaptic "background" noise (Destexhe and Pare, 1999); in addition, multitudes of various neurotransmitters are released (Lewis and O'Donnell, 2000; Blackwell et al., 2003). Together, these and the nonlinear dendritic processing at depolarized membrane potentials commonly reached during the up-state (Johnston et al., 1999; Williams and Stuart, 2000) profoundly affect synaptic integration and dendritic processing during up-states. The present study demonstrates that a timing function exists that translates the delay between a transition into the up-state and action potential firing into dendritic calcium levels through NMDA-dependent mechanisms. These findings thus provide the important first step to uniting the concept of spike-time-dependent plasticity and up-state generation and in- troducing timing of single action potentials as an important variable into striatal function.

\section{References}

Akins PT, Surmeier DJ, Kitai ST (1990) Muscarinic modulation of a transient K+ conductance in rat neostriatal neurons. Nature 344:240-242.

Bi GQ, Poo MM (1998) Synaptic modifications in cultured hippocampal neurons: dependence on spike timing, synaptic strength, and postsynaptic cell type. J Neurosci 18:10464-10472.

Blackwell KT, Czubayko U, Plenz D (2003) Quantitative estimate of synaptic inputs to striatal neurons during up and down states in vitro. J Neurosci 23:9123-9132.

Calabresi P, Maj R, Pisani A, Mercuri NB, Bernardi G (1992a) Long-term synaptic depression in the striatum-physiological and pharmacological characterization. J Neurosci 12:4224-4233.

Calabresi P, Pisani A, Mercuri NB, Bernardi G (1992b) Long-term potentiation in the striatum is unmasked by removing the voltage-dependent magnesium block of NMDA receptor channels. Eur J Neurosci 4:929-935.

Cepeda C, Levine MS (1998) Dopamine and N-methyl-D-aspartate receptor interactions in the neostriatum. Dev Neurosci 20:1-18.

Czubayko U, Plenz D (2002) Fast synaptic transmission between striatal spiny projection neurons. Proc Natl Acad Sci USA 99:15764-15769.

Denk W, Yuste R, Svoboda K, Tank DW (1996) Imaging calcium dynamics in dendritic spines. Curr Opin Neurobiol 6:372-378.

Destexhe A, Pare D (1999) Impact of network activity on the integrative properties of neocortical pyramidal neurons in vivo. J Neurophysiol 81:1531-1547.

Dunah AW, Standaert DG (2003) Subcellular segregation of distinct heteromeric NMDA glutamate receptors in the striatum. J Neurochem 85:935-943.

Gerfen CR, Wilson CJ (1996) The basal ganglia. In: Integrated systems of the CNS, Part III. Handbook of chemical neuroanatomy, Vol 12 (Swanson LW, Bjoerklund A, Hoekfelt T, eds), pp 371-468. Amsterdam: Elsevier Science BV.

Gotz T, Kraushaar U, Geiger J, Lubke J, Berger T, Jonas P (1997) Functional properties of AMPA and NMDA receptors expressed in identified types of basal ganglia neurons. J Neurosci 17:204-215.

Helmchen F, Imoto K, Sakmann B (1996) Ca2+ buffering and action potential-evoked $\mathrm{Ca} 2+$ signaling in dendrites of pyramidal neurons. Biophys J 70:1069-1081.

Hikosaka O, Sakamoto M, Usui S (1989a) Functional properties of monkey caudate neurons I. Activities related to saccadic eye movements. J Neurophysiol 61:780-798.

Hikosaka O, Sakamoto M, Usui S (1989b) Functional properties of monkey caudate neurons III. Activities related to expectation of target and reward. J Neurophysiol 61:814-832.

Jog MS, Kubota Y, Connolly CI, Hillegaart V, Graybiel AM (1999) Building neural representations of habits. Science 286:1745-1749.

Johnston D, Hoffman DA, Colbert CM, Magee JC (1999) Regulation of back-propagating action potentials in hippocampal neurons. Curr Opin Neurobiol 9:288-292.

Kerr JN, Plenz D (2002) Dendritic calcium encodes striatal neuron output during up-states. J Neurosci 22:1499-1512.

Kerr JN, Wickens JR (2001) Dopamine D-1/D-5 receptor activation is required for long-term potentiation in the rat neostriatum in vitro. J Neurophysiol 85:117-124.

Kitano K, Cateau H, Kaneda K, Nambu A, Takada M, Fukai T (2002) Twostate membrane potential transitions of striatal spiny neurons as evidenced by numerical simulations and electrophysiological recordings in awake monkeys. J Neurosci 22:RC230(1-6).

Koester HJ, Sakmann B (1998) Calcium dynamics in single spines during coincident pre- and postsynaptic activity depend on relative timing of back-propagating action potentials and subthreshold excitatory postsynaptic potentials. Proc Natl Acad Sci USA 95:9596-9601.

Koos T, Tepper JM (1999) Inhibitory control of neostriatal projection neurons by GABAergic interneurons. Nat Neurosci 2:467-472.

Lampl I, Reichova I, Ferster D (1999) Synchronous membrane potential fluctuations in neurons of the cat visual cortex. Neuron 22:361-374.

Lewis BL, O'Donnell P (2000) Ventral tegmental area afferents to the prefrontal cortex maintain membrane potential "up" states in pyramidal neurons via D(1) dopamine receptors. Cereb Cortex 10:1168-1175. 
Li-Smerin Y, Johnson JW (1996) Kinetics of the block by intracellular $\mathrm{Mg} 2+$ of the NMDA-activated channel in cultured rat neurons. J Physiol (Lond) 491:121-135.

Li-Smerin Y, Levitan ES, Johnson JW (2001) Free intracellular $\mathrm{Mg}(2+)$ concentration and inhibition of NMDA responses in cultured rat neurons. J Physiol (Lond) 533:729-743.

Lovinger DM, Tyler EC, Merritt A (1993) Short- and long-term synaptic depression in rat neostriatum. J Neurophysiol 70:1937-1949.

Magee JC, Johnston D (1997) A synaptically controlled, associative signal for Hebbian plasticity in hippocampal neurons. Science 275:209-213.

Mahon S, Delord B, Deniau JM, Charpier S (2000) Intrinsic properties of rat striatal output neurones and time-dependent facilitation of cortical inputs in vivo. J Physiol (Lond) 527:345-354.

Mahon S, Deniau JM, Charpier S (2001) Relationship between EEG potentials and intracellular activity of striatal and cortico-striatal neurons: an in vivo study under different anesthetics. Cereb Cortex 11:360-373.

Markram H, Lübke J, Frotscher M, Sakmann B (1997) Regulation of synaptic efficacy by coincidence of postsynaptic APs and EPSPs. Science 275:213-215.

Nisenbaum ES, Wilson CJ (1995) Potassium currents responsible for inward and outward rectification in rat neostriatal spiny projection neurons. J Neurosci 15:4449-4463.

Nisenbaum ES, Xu ZC, Wilson CJ (1994) Contribution of a slowly inactivating potassium current to the transition to firing of neostriatal spiny projection neurons. J Neurophysiol 71:1174-1189.

Oorschot DE (1996) Total number of neurons in the neostriatal, pallidal, subthalamic, and substantia nigra nuclei of the rat basal ganglia: a stereological study using the Cavalieri and optical disector methods. J Comp Neurol 366:580-599.

Plenz D (2003) When inhibition goes incognito: feedback interaction between spiny projection neurons in striatal function. Trends Neurosci 26:436-443.

Plenz D, Aertsen A (1996) Neuronal dynamics in cortex-striatum cocultures. II. Spatio-temporal characteristics of neuronal activity. Neuroscience 70:893-924.

Plenz D, Kitai ST (1998) "Up" and "down" states in striatal medium spiny neurons simultaneously recorded with spontaneous activity in fastspiking interneurons studied in cortex-striatum-substantia nigra organotypic cultures. J Neurosci 18:266-283.

Reynolds JN, Hyland BI, Wickens JR (2001) A cellular mechanism of reward-related learning. Nature 413:67-70.

Sandstrom MI, Rebec GV (2003) Characterization of striatal activity in conscious rats: contribution of NMDA and AMPA/kainate receptors to both spontaneous and glutamate-driven firing. Synapse 47:91-100.

Schiller J, Schiller Y, Clapham DE (1998) NMDA receptors amplify calcium influx into dendritic spines during associative pre- and postsynaptic activation. Nat Neurosci 1:114-118.
Schultz W, Romo R (1988) Neuronal activity in the monkey striatum during the initiation of movements. Exp Brain Res 71:431-436.

Standaert DG, Friberg IK, Landwehrmeyer GB, Young AB, Penney Jr JB (1999) Expression of NMDA glutamate receptor subunit mRNAs in neurochemically identified projection and interneurons in the striatum of the rat. Brain Res Mol Brain Res 64:11-23.

Stern EA, Kincaid AE, Wilson CJ (1997) Spontaneous subthreshold membrane potential fluctuations and action potential variability of rat corticostriatal and striatal neurons in vivo. J Neurophysiol 77:1697-1715.

Stern EA, Jaeger D, Wilson CJ (1998) Membrane potential synchrony of simultaneously recorded striatal spiny neurons in vivo. Nature 394:475-478.

Stuart GJ, Hausser M (2001) Dendritic coincidence detection of EPSPs and action potentials. Nat Neurosci 4:63-71.

Surmeier DJ, Kitai ST (1993) D1 and D2 dopamine receptor modulation of sodium and potassium currents in rat neostriatal neurons. In: Chemical signalling in the basal ganglia. Progress in brain research, Vol 99 (Arbuthnott GW, Emson PC, eds), pp 309-324. Amsterdam: Elsevier Science BV.

Surmeier DJ, Bargas J, Kitai ST (1989) Two types of A-current differing in voltage-dependence are expressed by neurons of the rat neostriatum. Neurosci Lett 103:331-337.

Tunstall MJ, Oorschot DE, Kean A, Wickens JR (2002) Inhibitory interactions between spiny projection neurons in the rat striatum. J Neurophysiol 88:1263-1269.

Wang H, Pickel VM (2000) Presence of NMDA-type glutamate receptors in cingulate corticostriatal terminals and their postsynaptic targets. Synapse 35:300-310.

Waters J, Larkum M, Sakmann B, Helmchen F (2003) Supralinear $\mathrm{Ca}^{2+}$ influx into dendritic tufts of layer $2 / 3$ neocortical pyramidal neurons in vitro and in vivo. J Neurosci 23:8558-8567.

Wickens JR, Wilson CJ (1998) Regulation of action-potential firing in spiny neurons of the rat neostriatum in vivo. J Neurophysiol 79:2358-2364.

Williams SR, Stuart GJ (2000) Backpropagation of physiological spike trains in neocortical pyramidal neurons: implications for temporal coding in dendrites. J Neurosci 20:8238-8246.

Wilson CJ, Kawaguchi Y (1996) The origins of two-state spontaneous membrane potential fluctuations of neostriatal spiny neurons. J Neurosci 16:2397-2410.

Wollmuth LP, Kuner T, Sakmann B (1998) Intracellular Mg2 + interacts with structural determinants of the narrow constriction contributed by the NR1-subunit in the NMDA receptor channel. J Physiol (Lond) 506:33-52.

Yuste R, Majewska A, Cash SS, Denk W (1999) Mechanisms of calcium influx into hippocampal spines: heterogeneity among spines, coincidence detection by NMDA receptors, and optical quantal analysis. J Neurosci 19:1976-1987. 